\title{
Pengembangan Keprofesian Berkelanjutan (PKB) dalam kaitannya dengan kompetensi dan praktik pembelajaran guru matematika SMA
}

\author{
Theresia Veni Tri Nugraheni ${ }^{1 *}$, Jailani ${ }^{2}$ iD \\ ${ }^{1}$ UPH College, Tangerang, Indonesia \\ 2 Department of Mathematics Education, Universitas Negeri Yogyakarta, Yogyakarta, Indonesia \\ * Corresponding Author. E-mail: theresiaveni@gmail.com
}

\begin{tabular}{ll}
\hline \multicolumn{1}{c}{ ARTICLE INFO } & \multicolumn{1}{c}{ ABSTRACT } \\
\hline Article History: & Penelitian ini bertujuan untuk mengeksplorasi Pengembangan Keprofesian Berkelanjutan (PKB) \\
Received: 22 Sept. 2020 & dalam kaitannya dengan kompetensi dan praktik pembelajaran yang dilakukan guru mate- \\
Revised: 15 October 2020 & matika SMA di Kabupaten Kulon Progo. Penelitian ini merupakan penelitian deskriptif meng- \\
Accepted: 2 Nov. 2020 & gunakan metode campuran, dengan desain penelitian convergent parallel design. Subjek dalam \\
& penelitian ini adalah seluruh guruSMA peserta Ujian Kompetensi Guru (UKG) matematika tahun \\
Keywords: & 2015 di Kabupaten Kulon Progo yang berjumlah 33 guru. Teknik pengumpulan data yang digu- \\
Pengembangan Keprofe- & nakan adalah tes, angket, observasi, dokumentasi, dan wawancara. Teknik analisis data yang \\
sian Berkelanjutan (PKB), & digunakan untuk data kuantitatif yaitu deskriptif dan Partial Least Squares Structural Equation \\
Kompetensi guru, & Modeling (PLS-SEM). Analisis data kualitatif dianalisis melalui pengkategorian, reduksi data, \\
Praktik pembelajaran & penyajian data, dan penarikan kesimpulan. Hasil penelitian menunjukkan bahwa: (1) terdapat \\
matematika, & pengaruh yang signifikan PKB terhadap kompetensi guru matematika SMA di Kabupaten Kulon \\
Continuing Professional & Progo dengan nilai prediksi sebesar 0,360 ( $t=2,51)$; dan (2) terdapat pengaruh yang signifikan \\
Development (CPD), & PKB terhadap praktik pembelajaran guru matematika SMA di Kabupaten Kulon Progo dengan \\
Math teaching practice. & nilai prediksi sebesar 0,402 $(t=2,25)$.
\end{tabular}

This study aimed to explore Continuing Professional Development (CPD) in relation to the competence and teaching practice conducted by senior high school mathematics teachers in Kulon Progo Regency. This study was descriptive research using a mixed-method with convergent parallel design. The research subject was all senior high school mathematics teachers in Kulon Progo Regency who participated in the Teacher Competency Test (or UKG) in 2015, and the subject applied was 33 teachers. The data collection was conducted through a test, questionnaire, documentation, observation, and interview. The data analysis used was descriptive and Partial Least Squares Structural Equation Modeling (PLS-SEM). Qualitative data was analyzed through data categorization, data reduction, data presentation, and conclusion drawing. The results of the study showed that: (1) there was a significant influence CPD toward competence of senior high school mathematics teachers in Kulon Progo Regency with prediction value 0.360 ( $t$ = 2.51); and (2) there was a significant influence CPD toward teaching practice of senior high school mathematics teachers in Kulon Progo Regency with prediction value 0.402 ( $t=2.25$ ).

This is an open access article under the CC-BY-SA license

\section{How to Cite:}

Nugraheni, T. V. T., \& Jailani, J. (2020). Pengembangan keprofesian berkelanjutan (PKB) dalam kaitannya dengan kompetensi dan praktik pembelajaran guru matematika SMA. Pythagoras: Jurnal Pendidikan Matematika, 15(1), 48-60. https://doi.org/10.21831/pg.v15i1.34601

https://doi.org/10.21831/pg.v15i1.34601

\section{PENDAHULUAN}

Belajar sepanjang hayat (lifelong learning) merupakan hal yang penting untuk dilakukan. Belajar sepanjang hayat merupakan proses yang perlu ada dalam pengembangan sumber daya manusia untuk memperbaharui keterampilan dan pengetahuan agar dapat menyesuaikan diri dengan perubahan zaman (Das, 2011, p.14; Klercq, 2016, p.294). Bahkan belajar sepanjang hayat merupakan tema pokok United Nations Educational, Scientific, and Cultural Organization (UNESCO) sejak tahun 1972 (Power \& Maclean, 2013, p.29). Belajar sepanjang hayat meru- 
Theresia Veni Tri Nugraheni, Jailani

pakan urgensi bagi bangsa Indonesia. Hal ini dilatarbelakangi kondisi masyarakat Indonesia, yaitu banyak pengangguran, bertambahnya penduduk miskin, dan populasi penduduk yang semakin meningkat (Hufad et al., 2010). Kondisi ini dapat menghambat bangsa Indonesia dalam menghadapi Masyarakat Ekonomi Asean (MEA). Oleh karena itu, bangsa Indonesia perlu untuk mempersiapkan Sumber Daya Manusia (SDM) yang berkualitas dalam menghadapi MEA.

Pendidikan merupakan salah satu hal yang diperlukan dalam mempersiapkan SDM yang berkualitas. Untuk menghadapi MEA diperlukan korelasi input penunjang SDM yang meliputi pendidikan, kesehatan, teknologi, dan komunikasi (Pratiwi \& Mahmudah, 2012). Rendahnya kualitas pendidikan SDM akan menghambat dalam pelaksanaan MEA bagi bangsa Indonesia. Selain itu, berdasarkan data dari United Nation Development Programme (UNDP, 2015, p.48) diperoleh bahwa indeks perkembangan manusia (Human Developement Indeks) Indonesia menduduki peringkat 110 dari 188 negara. Hal tersebut menggambarkan bahwa kualitas pendidikan di Indonesia perlu diperbaiki. Perbaikan kualitas pendidikan tidak mungkin dapat terwujud hanya dengan melakukan peningkatan sarana dan prasarana, serta perubahan kurikulum tanpa memperhatikan kualitas guru. Guru memiliki peranan penting dalam perbaikan kualitas pendidikan, karena kualitas guru memiliki hubungan yang kuat dengan pencapaian hasil belajar peserta didik (Ambusaidi \& Yang, 2019; Buddin \& Zamarro, 2009; Darling-Hammond, 2000; Seebruck, 2015; Stronge et al., 2007).

Guru adalah ujung tombak dalam peningkatan kualitas pendidikan. Guru memiliki peran dalam kemajuan dan peningkatan kualitas pendidikan karena guru adalah pusat perubahan. Oleh karena itu, guru haruslah memiliki kompetensi yang distandarkan oleh pemerintah guna mendukung adanya peningkatan kualitas pendidikan. Kompetensi merupakan kombinasi dari pengetahuan, keterampilan, sikap, nilai, motivasi, pengalaman, dan keyakinan sebagai dasar penguasaan yang dimiliki seseorang agar berhasil dalam pekerjaannya (Gupta et al., 2007; Kunter et al., 2013). Namun kenyataannya, dilihat dari rata-rata skor kompetensi guru dalam mengikuti Ujian Kompetensi Guru (UKG), hasilnya belum menggembirakan. Padahal kompetensi guru berhubungan dengan kualitas pembelajaran matematika (Hill et al., 2008; Phin, 2014) dan prestasi belajar siswa (Hill et al., 2008).

Berdasarkan hasil UKG pada tahun 2015, diperoleh rata-rata nasional 53,02, sementara standar kompetensi minimum yang diharapkan adalah 55 (Maulipaksi, 2016). Secara khusus, hasil UKG matematika SMA di provinsi Daerah Istimewa Yogyakarta (DIY) tahun 2015 disajikan pada Tabel 1 (PPPPTK Matematika, 2015).

Tabel 1. Hasil UKG matematika SMA tahun 2015 di Provinsi Daerah Istimewa Yogyakarta

\begin{tabular}{clc}
\hline No. & Kota/Kabupaten & Rata-rata \\
\hline 1. & Kabupaten Bantul & 78,34 \\
2. & Kabupaten Sleman & 76,94 \\
3. & Kabupaten Gunung Kidul & 73,72 \\
4. & Kota Yogyakarta & 73,90 \\
5. & Kabupaten Kulon Progo & 73,43 \\
\hline & Rata-rata & 75,27 \\
\hline
\end{tabular}

Berdasarkan data pada Tabel 1, dapat dilihat bahwa rata-rata hasil UKG matematika SMA di Kabupaten Kulon Progo berada pada peringkat 5 atau terakhir dibandingkan dengan kota/kabupaten lain di provinsi DIY dan berada di bawah rata-rata Provinsi DIY. Kota/Kabupaten di DIY yang berada di bawah rata-rata provinsi DIY, yaitu Kabupaten Gunung Kidul, Kota Yogyakarta, dan Kabupaten Kulon Progo. Oleh karena hasil UKG guru matematika SMA di Kabupaten Kulon Progo berada pada peringkat terakhir, maka peneliti tertarik untuk memfokuskan penelitian dengan subyek guru matematika SMA di Kabupaten Kulon Progo.

Salah satu cara yang dapat dilakukan guru untuk meningkatkan kualitasnya sebagai pendidik profesional yaitu dengan pengembangan profesi. Pengembangan profesi guru hendaknya terjadi secara berkelanjutan dan merupakan proses sepanjang hayat. Selain itu, pengembangan profesi guru dapat memberi pengaruh pada pengetahuan dan keterampilan guru, meningkatkan praktik mengajar guru, dan meningkatkan pencapaian peserta didik (Akalu, 2016; Desimone, 2009; Guskey, 2000). Pemerintah Indonesia juga sudah berupaya agar guru secara berkelanjutan meningkatkan kompetensinya dengan mencetuskan Pengembangan Keprofesian Berkelanjutan (PKB). PKB dilaksanakan sesuai dengan kebutuhan guru untuk mencapai standar kompetensi profesi atau meningkatkan kompetensinya di atas standar kompetensi profesinya yang sekaligus berimplikasi kepada perolehan angka kredit untuk kenaikan pangkat/jabatan fungsional guru (Kemendiknas, 2010). Istilah Pengembangan Keprofesian Ber- 
kelanjutan (PKB) dalam perspektif internasional dikenal dengan Continuing Profesional Development (CPD). Istilah PKB atau CPD sering digunakan untuk menggambarkan upaya guru dalam mengembangkan pengetahuan dan keterampilannya. Upaya PKB ini diperlukan karena guru perlu untuk memperbaharui diri dengan tujuan untuk mengimbangi perubahan zaman. Hal ini sejalan dengan pendapat Day (2002), bahwa PKB diperlukan semua guru untuk mengimbangi perubahan, untuk meninjau dan memperbaharui pengetahuan, keterampilan, dan visi tentang mengajar yang baik.

Collin et al., (2012) menjelaskan bahwa PKB dapat diperoleh dalam berbagai bentuk dari rangkaian pendidikan formal sampai belajar melalui praktik kerja setiap harinya. PKB ditargetkan untuk mendukung guru dalam memperoleh pengetahuan, ketrampilan, dan kepercayaan diri yang diperlukan untuk mengubah praktik guru dan berkontribusi untuk pembelajaran yang lebih baik (Braund et al., 2011). Sementara itu, Bailey (2011) menyatakan bahwa melalui PKB berarti secara terus-menerus guru memperbaharui pengetahuan profesional, keterampilan pribadi dan profesional, dan kompetensi yang dimilikinya. Berdasarkan hasil dari beberapa penelitian, ditemukan bahwa PKB guru dapat meningkatkan kinerja, kompetensi, dan keterampilan. Hasil penelitian Shah et al. (2015) menunjukkan bahwa PKB dapat meningkatkan kinerja guru pada aspek persiapan dan perencanaan pembelajaran, manajemen kelas, monitoring dan evaluasi, dan keterampilan pedagogik guru. Hasil penelitian Powell et al. (2003) menunjukkan bahwa sebagian besar guru yang mengikuti PKB menyatakan bahwa mereka mendapatkan pengalaman positif dan kebutuhan pengembangan profesi mereka terpenuhi. Selain itu, dalam penelitian tersebut juga ditemukan bahwa guru mendapatkan manfaat dari PKB sehubungan dengan pemikiran dan pengetahuan profesional, kepercayaan diri, praktik pembelajaran, dan peningkatan manajemen kelas. Namun, PKB di beberapa wilayah di Indonesia masih belum menggembirakan. Berdasarkan hasil penelitian Widodo et al. (2015), diperoleh bahwa hanya dua guru dari 15 responden guru Fisika SMA di Kabupaten Kendal yang telah mampu membuat karya ilmiah berupa penelitian tindakan kelas. Sementara hasil penelitian Wibowo dan Jailani (2014) menunjukkan bahwa persentase jumlah guru matematika SMP di Kabupaten Wonosobo yang telah melaksanakan kegiatan pengembangan profesi secara umum masih pada kategori sedikit.

Pengembangan profesi guru dapat memberi pengaruh pada pencapaian hasil belajar peserta didik. Hal ini senada dengan pendapat Wallace (2009) bahwa pengembangan profesi guru dapat memberikan pengaruh yang signifikan pada pencapaian peserta didik jika pengembangan profesi tersebut diterapkan dalam praktik pembelajaran. Faktanya prestasi belajar peserta didik SMA di Kabupaten Kulon Progo dengan melihat hasil UN matematika belum menggembirakan. Berdasarkan data hasil UN matematika untuk program IPA maupun IPS tahun pelajaran 2014/2015 menunjukkan bahwa rata-rata hasil UN peserta didik SMA/MA di Kabupaten Kulon Progo berada di posisi terakhir dari kota/kabupaten di Provinsi DIY dan berada di bawah rata-rata provinsi DIY (BSNP, 2015). Data hasil UN matematika tahun pelajaran 2015/2016 menunjukkan bahwa rata-rata hasil UN peserta didik SMA/MA di Kabupaten Kulon Progo berada di posisi terakhir untuk program IPA dan peringkat 4 untuk program IPS dari kota/kabupaten di Provinsi DIY (BSNP, 2016). Data hasil UN matematika juga menunjukkan bahwa pada kedua tahun pelajaran tersebut rata-rata hasil UN matematika Kabupaten Kulon Progo berada di bawah rata-rata provinsi DIY. Melihat kondisi tersebut, maka pengembangan profesi guru urgen dilakukan.

Pengembangan profesi guru hendaknya dilakukan secara berkelanjutan agar guru dapat terus memperbaharui pengetahuan dan keterampilannya. Hasil penelitian Sabah et al. (2014) menunjukkan bahwa kegiatan PKB yang diikuti sebagian besar guru adalah mengenai pedagogical knowledge. Sementara, hasil penelitian Doherty (2011) menunjukkan bahwa peserta kegiatan Educational Professional Development (EDP) yang berisikan pengembangan profesi untuk mengajar memberikan tanggapan yang positif mengenai workshop yang diikuti dalam EDP berkaitan dengan teknologi. Namun, hanya sebagian kecil yang menerapkannya dalam praktik pembelajaran. Pengembangan profesi guru juga berperan dalam meningkatkan kompetensi guru serta berkontribusi pada pencapaian hasil belajar peserta didikjika pengembangan profesi guru diterapkan dalam praktik pembelajaran. Pengujian kompetensi guru perlu dilakukan secara rutin untuk mengetahui kualitas guru dan juga untuk mengetahui pengembangan profesi yang berkontribusi pada peningkatan kompetensi guru (Blömeke \& Delaney, 2012). Dalam menguji kompetensi guru, selain menguji pengetahuan guru diperlukan juga melakukan pengamatan praktik pembelajaran guru di kelas. Hal ini dilakukan untuk memastikan keterampilan yang dimiliki guru dalam praktik pembelajaran.

Beberapa peneliti pernah melakukan penelitian terkait PKB, kompetensi guru, dan praktik pembelajaran. Sebagai contoh, penelitian Kartowagiran (2011) melaporkan bahwa kemampuan guru dalam menyusun rencana pembelajaran dan pelaksanaan pembelajaran sudah baik, namun pengembangan profesi guru hasilnya belum 
menggembirakan. Dalam penelitian Kartowagiran tersebut, dilakukan analisis terkait praktik pembelajaran dan pengembangan profesi guru, namun belum fokus pada kompetensi guru dan eksplorasi keterkaitan PKB terhadap kompetensi guru dan praktik pembelajaran. Penelitian Aziz dan Akhtar (2014) menunjukkan bahwa guru yang mengikuti pelatihan lebih kompeten dibandingkan dengan guru yang tidak mengikuti pelatihan dilihat pada kompetensi pedagogik, pengelolaan dan penilaian, serta penelitian. Penelitian tersebut belum fokus pada praktik pembelajaran dan eksplorasi keterkaitan PKB terhadap praktik pembelajaran. Oleh karena dalam penelitian-penelitian yang dilakukan oleh peneliti sebelumnya belum mengeksplorasi keterkaitan antara PKB dengan kompetensi dan praktik pembelajaran guru, maka peneliti tertarik untuk mengeksplorasi PKB dalam kaitannya dengan kompetensi guru dan praktik pembelajaran yang dilakukan oleh guru. Dengan demikian, tujuan penelitian ini adalah untuk mengeksplorasi PKB dalam kaitannya dengan kompetensi dan praktik pembelajaran guru matematika SMA di Kabupaten Kulon Progo.

\section{METODE}

Penelitian ini merupakan penelitian deskriptif yang menggunakan metode kuantitatif dan kualitatif (mixed methods) dengan desain penelitian convergent parallel design. Dalam convergent parallel design, peneliti mengumpulkan data kuantitatif dan kualitatif secara bersamaan. Creswell (2012) menjelaskan bahwa pengumpulan data kuantitatif dan kualitatif dalam convergent parallel design dilakukan secara bersamaan, data dibandingkan atau dihubungkan, dan hasil yang diperoleh digunakan untuk menjawab rumusan masalah penelitian. Subjek dalam penelitian ini adalah seluruh guru peserta UKG matematika tahun 2015 dari 13 SMA di Kabupaten Kulon Progo pada lingkup Kementerian Pendidikan dan Kebudayaan. Subjek penelitian terdiri dari 33 guru dengan rincian dua guru berasal dari sekolah swasta dan 31 guru berasal dari sekolah negeri.

Terdapat tiga variabel dalam penelitian ini, yaitu PKB, kompetensi guru, dan praktik pembelajaran. Data PKB diperoleh dari data kuantitatif berdasarkan hasil angket dan dicocokkan dengan data kualitatif, yaitu data wawancara, observasi, dan studi dokumen. Validitas instrumen dalam penelitian ini, yaitu angket yang diisi guru dibuktikan dengan validitas isi dan validitas konstruk, sedangkan validitas instrumen lembar observasi, lembar studi dokumen, lembar penilaian dokumen, angket peserta didik, dan lembar wawancara dibuktikan dengan validitas isi. Validitas isi dilakukan oleh dua ahli, yaitu satu dosen dari Program Studi Pendidikan Matematika UNY dan satu tenaga ahli dari Pusat Pengembangan dan Pemberdayaan Pendidik dan Tenaga Kependidikan (PPPPTK) Matematika Kemendikbud.

Terdapat dua angket utama yang digunakan dalam penelitian ini, yaitu angket $A$ dan B. Angket A merupakan angket yang berkaitan dengan PKB. Angket $A$ terdiri dari 35 butir pernyataan yang digunakan untuk mengungkap gambaran keterlaksanaan PKB pada rentang waktu tahun 2012-2017. Angket A atau angket pelaksanaan PKB merupakan angket tertutup yang memungkinkan responden memilih jawaban berdasarkan keadaan yang sebenarnya. Angket $B$ merupakan angket yang berkaitan dengan praktik pembelajaran. Angket $B$ terdiri dari angket B.1, B.2, B.3, B.4, dan B.5. Angket B.1, B.2, B.3, dan B.4 diisi oleh guru yang bersangkutan, sedangkan angket B.5 diisi oleh peserta didik yang diajar oleh guru yang bersangkutan. Skala angket yang digunakan adalah skala Likert. Angket B.1 terdiri dari 20 butir pernyataan yang digunakan untuk mengungkap gambaran kegiatan persiapan dan perencanaan pembelajaran, angket B. 2 terdiri dari 25 butir pernyataan digunakan untuk mengungkap gambaran kegiatan pelaksanaan pembelajaran, angket B.3 terdiri dari 15 butir pernyataan yang digunakan untuk mengungkap gambaran kegiatan penilaian hasil belajar, angket B.4 terdiri dari 15 butir pernyataan yang digunakan untuk mengungkap gambaran kegiatan refleksi dan evaluasi pembelajaran, sedangkan angket B.5 terdiri dari 30 butir pernyataan yang digunakan untuk memverifikasi, mengubah, dan memperluas informasi kegiatan praktik pembelajaran yang telah dilakukan guru yang bersangkutan.

Peneliti juga mengumpulkan data melalui wawancara kepada subjek penelitian. Wawancara ini dilakukan untuk memverifikasi dan memperluas informasi yang diperoleh dari angket $A$. Peneliti juga melakukan observasi untuk memperoleh gambaran tentang pelaksanaan pembelajaran guru di kelas. Selain itu, peneliti juga menggunakan lembar studi dokumen yang berbentuk checklist dan digunakan untuk mencatat kelengkapan dokumen PKB dan dokumen praktik pembelajaran.

Aspek dan indikator PKB diperoleh melalui sintesis teori dari para ahli (misalnya, Croft et al., 2010; Desimone et al., 2002; Kemendiknas, 2010; Opfer \& Pedder, 2010; Ozdemir, 2013). Tabel 2 menampilkan aspek dan indikator PKB yang digunakan dalam angket PKB dan wawancara dalam penelitian ini. 
Tabel 2. Aspek dan indikator PKB

\begin{tabular}{ll}
\hline Aspek & Indikator \\
\hline Peningkatan pengetahuan & Membaca literatur \\
& Pendidikan formal \\
& Pelatihan profesional \\
\multirow{3}{*}{ Peningkatan keterampilan } & Pengembangan praktik pembelajaran \\
& Kolaborasi dengan rekan sejawat \\
Penyebarluasan pengetahuan & Publikasi tulisan ilmiah \\
& Pemakalah pada forum ilmiah \\
\hline
\end{tabular}

Data kompetensi guru diperoleh dari data hasil UKG tahun 2015 (PPPPTK Matematika, 2015) dengan terlebih dulu dilakukan pencocokan indikator antara indikator UKG tahun 2015 dengan indikator kompetensi guru menurut para ahli yang digunakan dalam penelitian ini. Dalam penelitian ini dua ranah kompetensi guru yang dianalisis, yaitu ranah professional knowledge dan professional practice. Kedua ranah ini diperoleh berdasarkan sintesis teori para ahli (misalnya, Australian Institute for Teaching and School Leadership, 2011; Council of Chief State School Officers, 2011; Department for Education, 2011; Presiden Republik Indonesia, 2008). Tabel 3 menampilkan ranah dan indikator kompetensi guru yang digunakan dalam penelitian ini.

Tabel 3. Ranah dan indikator kompetensi guru

\begin{tabular}{ll}
\hline Aspek & Indikator \\
\hline Professional knowledge & Pengetahuan tentang peserta didik \\
& Pengetahuan tentang matematika yang \\
& Pengetahuan tentang bagaimana peserta didik belajar matematika \\
Professional practice & Perencanaan pembelajaran \\
& Pelaksanaan pembelajaran \\
& Penilaian hasil belajar \\
\hline
\end{tabular}

Berkaitan dengan praktik pembelajaran, yaitu dalam (1) aspek persiapan dan perencanaan pembelajaran, peneliti melakukan pencocokan data antara angket persiapan dan perencanaan pembelajaran (angket B.1) dengan lembar penilaian dokumen; (2) aspek pelaksanaan pembelajaran, peneliti melakukan pencocokan data antara angket pelaksanaan pembelajaran (angket B.2), angket praktik pembelajaran yang diisi peserta didik, observasi, dan studi dokumen, (3) aspek penilaian hasil belajar, peneliti melakukan pencocokan data antara angket penilaian hasil belajar (angket B.3), angket praktik pembelajaran yang diisi peserta didik, dan studi dokumen, dan (4) aspek refleksi dan evaluasi pembelajaran, peneliti melakukan pencocokan data antara angket refleksi dan evaluasi pembelajaran (angket B.4), angket praktik pembelajaran yang diisi peserta didik, observasi, dan studi dokumen. Hasil pencocokan seluruh data tersebut digunakan untuk menarik kesimpulan terkait praktik pembelajaran. Aspek dan indikator yang diukur terkait praktik pembelajaran diperoleh melalui sintesis teori para ahli (misalnya, Bell, 1978; Brown, 1995; Chen et al., 2011; Cohen et al., 2004; Goe, 2007; Haynes, 2010; Kyriacou, 2007). Tabel 4 menampilkan aspek dan indikator praktik pembelajaran yang diukur dalam penelitian ini.

Hubungan antara PKB terhadap kompetensi guru dan praktik pembelajaran dianalisis menggunakan Partial Least Squares Structural Equation Modeling (PLS-SEM). Peneliti menggunakan PLS-SEM dengan pertimbangan bahwa populasi pada penelitian ini berukuran kecil sehingga responden yang digunakan juga sedikit. Selain itu, data pada penelitian ini juga tidak berdistribusi normal multivariat. Hair et al. (2014, p. 15) mengemukakan bahwa PLSSEM dapat digunakan pada sampel dengan ukuran kecil dan tidak memerlukan asumsi data berdistribusi normal. Chin dan Newsted (1999) menyatakan bahwa penggunaan PLS-SEM direkomendasikan pada ukuran sampel minimal antara 30-100. Sementara, pada penelitian ini banyaknya sampel adalah 33 guru. Oleh karena itu, analisis yang sesuai adalah menggunakan PLS-SEM.

Data kualitatif dianalisis menggunakan model interaktif (Miles et al., 2014). Data yang dianalisis mengalami proses kondensasi data, penyajian data, dan penarikan kesimpulan. Kondensasi data adalah proses untuk memilih dan memfokuskan, mengabstraksi dan mengubah data yang muncul dalam pengumpulan data. Penyajian data adalah proses dalam menyusun dan meringkas data agar mempermudah dalam penyajian data. Sementara pena- 
rikan kesimpulan, yaitu dengan menggambarkan dan memverifikasi data. Penarikan kesimpulan dilakukan dengan melakukan pencocokan data antara data kuantitatif dan data kualitatif.

Tabel 4. Aspek dan indikator praktik pembelajaran

\begin{tabular}{ll}
\hline Aspek & Indikator \\
\hline Persiapan dan perencanaan pembelajaran & Pengembangan silabus \\
& Pengembangan RPP \\
Pelaksanaan pembelajaran & Kegiatan pendahuluan \\
& Kegiatan inti \\
& Kegiatan penutup \\
Penilaian hasil belajar & Perencanaan penilaian \\
& Pelaksanaan penilaian \\
Refleksi dan evaluasi pembelajaran & Pelaporan penilaian \\
& Persiapan dan perencanaan pembelajaran \\
& Pelaksanaan pembelajaran \\
& Penilaian hasil belajar \\
\hline
\end{tabular}

\section{HASIL PENELITIAN}

\section{Hasil Penelitian}

Sebelum mencari prediksi hubungan antar konstruk, peneliti merancang model pengukuran yang didasarkan pada konsep atau teori menurut pendapat para ahli. Model pengukuran dan model struktural yang menunjukkan hubungan antara PKB terhadap kompetensi guru dan praktik pembelajaran ditampilkan pada Gambar 1:

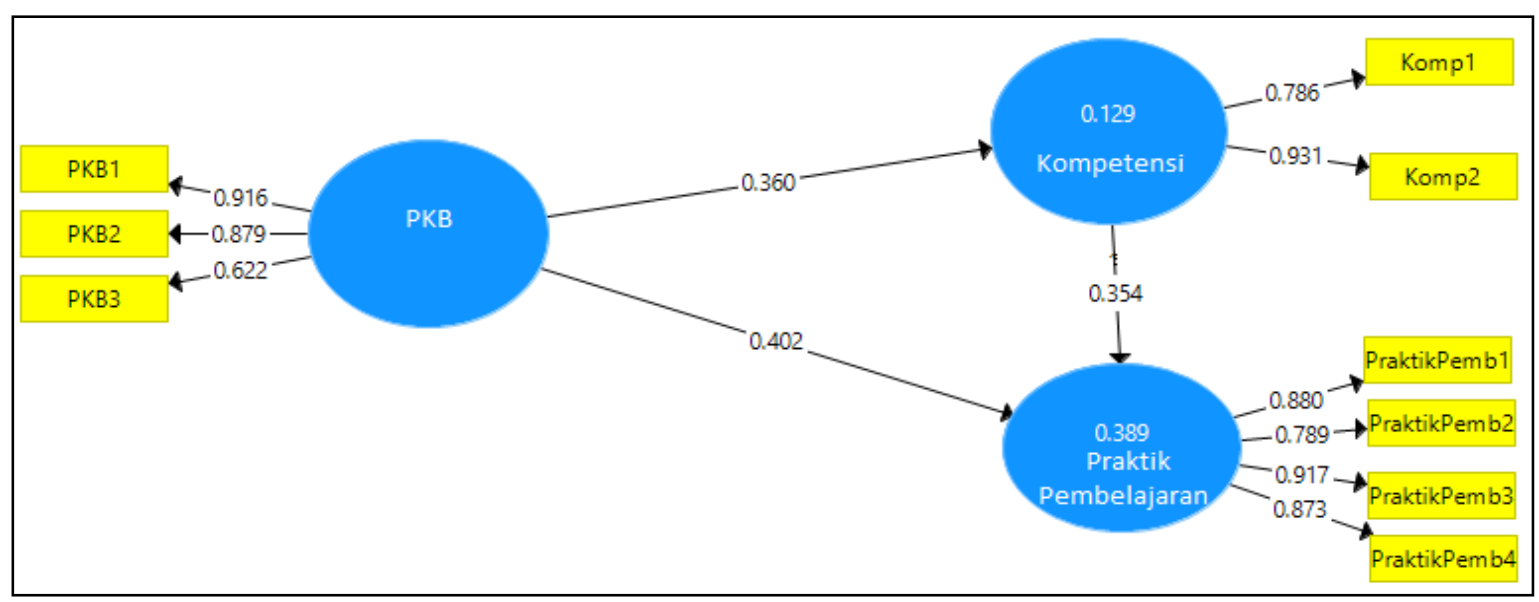

Gambar 1. Hubungan antara PKB terhadap kompetensi guru dan praktik pembelajaran

Pada Gambar 1, variabel terukur PKB1, PKB2, dan PKB3 secara berurutan mewakili variabel PKB pada aspek peningkatan pengetahuan, peningkatan keterampilan, dan penyebarluasan pengetahuan. Variabel terukur Komp1 dan Komp2 secara berurutan mewakili variabel kompetensi guru pada ranah professional knowledge dan professional practice. Sementara, variabel terukur PraktikPemb1, PraktikPemb2, PraktikPemb3, dan PraktikPemb4 secara berturut-turut mewakili variabel praktik pembelajaran pada kegiatan persiapan dan perencanaan pembelajaran, pelaksanaan pembelajaran, penilaian hasil belajar, serta refleksi dan evaluasi pembelajaran.

Selanjutnya peneliti, melakukan evaluasi model pengukuran (outer model) pada masing-masing variabel laten, yaitu PKB, kompetensi guru, dan praktik pembelajaran dengan melihat nilai outer loading, menguji validitas konstruk (validitas konvergen dan validitas diskriminan), dan mengestimasi reliabilitas (composite reliability). Tabel 5 menampilkan nilai outer loading pada model pengukuran. Berdasarkan Tabel 5, dapat dilihat bahwa pada variabel PKB, yaitu aspek penyebarluasan pengetahuan (PKB3) terdapat nilai loading kurang dari 0,7. Hair et al. (2014) menyatakan bahwa indikator dengan nilai loading kurang dari 0,4 harus benar-benar dibuang, sementara nilai loading antara 0,4 dan 0,7 dapat dipertimbangkan untuk dibuang. Namun, untuk menjaga keterwakilan indikator 
atau aspek PKB dalam penelitian ini maka indikator reflektif yang harus dibuang adalah indikator reflektif dengan nilai loading kurang dari 0,4. Berdasarkan hasil analisis yang ditampilkan pada Tabel 5 diperoleh bahwa seluruh nilai outer loading lebih dari 0,4 sehingga tidak ada indikator yang perlu untuk dibuang.

Tabel 5. Nilai outer loading

\begin{tabular}{lccc}
\hline & Kompetensi & PKB & $\begin{array}{c}\text { Praktik } \\
\text { pembelajaran }\end{array}$ \\
\hline Komp1 & 0,786 & & \\
Komp2 & 0,931 & & \\
PKB1 & & 0,916 & \\
PKB2 & & 0,879 & \\
PKB3 & 0,622 & \\
PraktikPemb1 & & & 0,880 \\
PraktikPemb2 & & & 0,789 \\
PraktikPemb3 & & & 0,917 \\
PraktikPemb4 & & & 0,873 \\
\hline
\end{tabular}

Selanjutnya, hasil analisis validitas konvergen model pengukuran disajikan pada Tabel 6. Hair et al. (2014) menyatakan bahwa nilai Average Variance Extracted (AVE) dalam validitas konvergen minimal harus lebih besar dari 0,5. Pada Tabel 6 dapat dilihat bahwa nilai AVE untuk variabel PKB, Kompetensi, dan Praktik Pembelajaran lebih dari 0,5 , sehingga validitas konvergen terpenuhi dan tidak ada masalah dengan validitas konvergen dari model pengukuran.

Tabel 6. Validitas konvergen model pengukuran

\begin{tabular}{lc}
\hline Variabel & Average Variance Extracted (AVE) \\
\hline PKB & 0,67 \\
Kompetensi & 0,74 \\
Praktik pembelajaran & 0,75 \\
\hline
\end{tabular}

Hair et al. (2014) menyatakan bahwa nilai loading dalam validitas diskriminan dari masing-masing butir terhadap konstruknya harus lebih dari nilai cross loading-nya. Berdasarkan Tabel 7, dapat dilihat bahwa masingmasing nilai loading dari Komp1 dan Komp2, yaitu 0,79 dan 0,93. Nilai loading untuk PKB1, PKB2, dan PKB3 secara berurutan, yaitu 0,92, 0,88, dan 0,62. Sementara, nilai loading untuk PraktikPem1, PraktikPemb2, PraktiPemb3, dan PraktikPemb4 secara berurutan adalah 0,88, 0,79, 0,92, dan 0,87. Hal tersebut membuktikan bahwa seluruh nilai loading masing-masing butir terhadap konstruknya lebih besar dari nilai cross loading-nya. Dengan demikian, dapat disimpulkan bahwa validitas diskriminan terpenuhi dan tidak ada masalah dengan validitas konvergen dari model pengukuran.

Tabel 7. Validitas diskriminan model pengukuran

\begin{tabular}{lccc}
\hline & Kompetensi & PKB & $\begin{array}{c}\text { Praktik } \\
\text { pembelajaran }\end{array}$ \\
\hline Komp1 & $\mathbf{0 , 7 9}$ & 0,31 & 0,24 \\
Komp2 & $\mathbf{0 , 9 3}$ & 0,32 & 0,55 \\
PKB1 & 0,43 & $\mathbf{0 , 9 2}$ & 0,46 \\
PKB2 & 0,21 & $\mathbf{0 , 8 8}$ & 0,54 \\
PKB3 & 0,17 & $\mathbf{0 , 6 2}$ & $-0,02$ \\
PraktikPemb1 & 0,47 & 0,56 & $\mathbf{0 , 8 8}$ \\
PraktikPemb2 & 0,38 & 0,37 & $\mathbf{0 , 7 9}$ \\
PraktikPemb3 & 0,51 & 0,38 & $\mathbf{0 , 9 2}$ \\
PraktikPemb4 & 0,34 & 0,50 & $\mathbf{0 , 8 7}$ \\
\hline
\end{tabular}

Selanjutnya hasil estimasi reliabilitas model pengukuran disajikan pada Tabel 8. Hair et al. (2014) menyatakan bahwa nilai estimasi composite reliability harus lebih dari 0,708. Berdasarkan Tabel 8 dapat dilihat bahwa hasil dari 
Theresia Veni Tri Nugraheni, Jailani

estimasi koefisien reliabilitas untuk variabel PKB, kompetensi, dan praktik pembelajaran lebih dari 0,708. Hal ini menunjukkan bahwa instrumen angket PKB, praktik pembelajaran, serta tes kompetensi guru memenuhi syarat minimal skor reliabel. Berdasarkan hasil output nilai outer loading, validitas konvergen, validitas diskriminan, dan composite reliability maka dapat disimpulkan bahwa tidak ada masalah dengan model pengukuran (outer model). Selanjutnya, peneliti melakukan evaluasi model struktural (inner model) untuk melihat hubungan antara PKB terhadap kompetensi guru dan praktik pembelajaran. Model struktural menampilkan hubungan jalur antar konstruk, sementara model pengukuran menampilkan hubungan antar konstruk dan indikator. Tabel 8 menampilkan bukti composite reliability pada model pengukuran.

Tabel 8. Composite reliability model pengukuran

\begin{tabular}{lc}
\hline Variabel & Composite realiability \\
\hline PKB & 0,85 \\
Kompetensi & 0,85 \\
Praktik Pembelajaran & 0,92 \\
\hline
\end{tabular}

Penarikan kesimpulan hubungan antara PKB terhadap kompetensi guru dan praktik pembelajaran dapat dilihat dari nilai prediksi, $t$ staitistik, dan nilai $R^{2}$. Pada penelitian ini, peneliti menggunakan taraf signifikansi $5 \%$. Hair et al. (2014) menjelaskan bahwa pada taraf signifikansi $5 \%(\alpha=0,05)$, nilai $t$ statistik diharapkan lebih dari 1,96. Sementara, nilai prediksi keterkaitan antara PKB terhadap kompetensi guru, dan praktik pembelajaran dapat dilihat dari output path coefficient. Garson (2016) mengemukakan bahwa path coefficient berada antara-1 sampai 1. Path coefficient yang semakin mendekati nilai mutlak 1 menunjukkan jalur terkuat, sedangkan path coefficient dengan nilai semakin mendekati 0 menunjukkan jalur terlemah. Selain itu, nilai positif pada path coefficient menunjukkan adanya pengaruh positif, sedangkan nilai negatif pada path coefficient menunjukkan adanya pengaruh negatif.

Hair at al. (2014) menyatakan bahwa nilai $R^{2}$ menggambarkan besarnya kemampuan variabel laten eksogen menjelaskan variabel endogen. Variabel laten eksogen adalah konstruk yang menjelaskan konstruk lainnya dalam model, sementara variabel laten endogen adalah konstruk yang dijelaskan oleh konstruk lainnya dalam model. Variabel laten eksogen dalam penelitian ini, yaitu PKB, sementara variabel laten endogen dalam penelitian ini adalah kompetensi guru dan praktik pembelajaran. Berkaitan dengan nilai $R^{2}$, Chin dan Newsted (1999) mengemukakan bahwa kriteria nilai $R^{2}$ sebesar $0,19,0,33$, dan 0,67 secara berturut-turut sebagai lemah, cukup, dan kuat. Tabel 9 menampilkan hubungan antara PKB terhadap kompetensi guru dan praktik pembelajaran.

Tabel 9. Hubungan antara PKB terhadap kompetensi guru dan praktik pembelajaran

\begin{tabular}{lccc}
\hline Hubungan & Nilai prediksi & $t$ & $R^{2}$ \\
\hline PKB $\rightarrow$ Kompetensi & 0,360 & $2,51^{*}$ & 0,129 \\
PKB $\rightarrow$ Praktik pembelajaran & 0,402 & $2,25^{*}$ & 0,389 \\
Kompetensi $\rightarrow$ Praktik pembelajaran & 0,354 & $2,82^{*}$ & \\
\hline
\end{tabular}

$* p<0,05$

Berdasarkan nilai $t$ statistik pada Tabel 9, PKB signifikan dalam memprediksi kompetensi guru dan praktik pembelajaran. Selain itu, kompetensi guru juga signifikan dalam memprediksi praktik pembelajaran. Temuan lain berdasarkan output PLS-SEM, yaitu diperoleh nilai $R^{2}$ untuk variabel kompetensi guru sebesar 0,129 , yang artinya nilai tersebut mengindikasikan bahwa variabel kompetensi guru dijelaskan oleh variabel PKB sebesar $12,9 \%$, sedangkan sisanya yaitu sebesar $87,1 \%$ dipengaruhi oleh variabel lain yang tidak terdapat dalam model penelitian. Sementara nilai $R^{2}$ untuk variabel praktik pembelajaran sebesar 0,389, yang mengindikasikan bahwa variabel praktik pembelajaran dijelaskan oleh variabel PKB dan kompetensi guru sebesar $38,9 \%$, sedangkan sisanya yaitu sebesar $61,1 \%$ dijelaskan oleh variabel lain yang tidak terdapat dalam model penelitian.

Selain itu, berdasarkan hasil angket PKB dan hasil studi dokumen, juga diperoleh informasi bahwa kegiatan PKB yang paling banyak dilakukan guru dibandingkan dengan kegiatan PKB lainnya, yaitu membaca literatur yang merupakan salah satu bentuk kegiatan PKB pada aspek peningkatan pengetahuan. Temuan penelitian juga menunjukkan bahwa kegiatan membaca literatur merupakan kegiatan yang memberikan kontribusi terbesar bagi banyak guru matematika SMA di Kabupaten Kulon Progo dalam meningkatkan kompetensi guru maupun praktik pembelajaran. Sementara itu, berdasarkan hasil wawancara, diperoleh informasi bahwa guru merasakan banyak 
manfaat dari pelatihan-pelatihan yang telah diikuti, terutama terkait praktik pembelajaran. Akan tetapi, baru sebagian guru yang telah menerapkan hasil pelatihan tersebut dalam pembelajaran matematika.

\section{PEMBAHASAN}

Hasil penelitian menunjukkan bahwa terdapat pengaruh yang signifikan antara PKB terhadap kompetensi guru matematika SMA di Kabupaten Kulon Progo dengan prediksi hubungan sebesar 0,360 dan terdapat pengaruh yang signifikan antara PKB terhadap praktik pembelajaran guru matematika SMA di Kabupaten Kulon Progo dengan prediksi hubungan sebesar 0,402 . Selain itu, temuan penelitian juga menunjukkan bahwa terdapat pengaruh yang signifikan antara kompetensi guru terhadap praktik pembelajaran guru matematika SMA di Kabupaten Kulon Progo dengan prediksi hubungan sebesar 0,354. Garson (2016) mengemukakan bahwa nilai positif pada path coefficient menunjukkan adanya pengaruh positif. Suhr (2008) mengemukakan bahwa path coeffcient di sekitar 0,3 berarti memberikan pengaruh sedang. Oleh karena itu, berdasarkan kriteria nilai prediksi tersebut maka dapat dikatakan bahwa PKB dapat memberikan pengaruh sedang terhadap kompetensi guru dan praktik pembelajaran. Selain itu, kompetensi guru juga dapat memberikan pengaruh sedang terhadap praktik pembelajaran.

Hasil penelitian menunjukkan bahwa terdapat keterkaitan antara PKB terhadap kompetensi guru dan praktik pembelajaran. Hasil ini sejalan dengan pendapat Desimone (2009), Guskey (2000), dan Akalu (2016) bahwa pengembangan profesi akan meningkatkan kompetensi (pengetahuan dan keterampilan) guru, meningkatkan praktik pembelajaran, dan selanjutnya dapat meningkatkan pencapaian peserta didik. Hal ini juga sesuai dengan pendapat Borko (2004) bahwa program pengembangan profesi yang intensif dapat mengubah atau meningkatkan pengetahuan guru dan praktik pembelajaran. Oleh karena itu, agar terdapat peningkatan kompetensi guru, khususnya pengetahuan guru dan juga praktik pembelajaran, hendaknya dilakukan kegiatan PKB secara intensif yang disesuaikan dengan kebutuhan guru dan juga perlu dirancang kegiatan PKB yang efektif bagi guru.

Berdasarkan hasil penelitian diperoleh bahwa variabel kompetensi guru dijelaskan oleh variabel PKB sebesar $12,9 \%$ sedangkan sisanya yaitu sebesar $87,1 \%$ dipengaruhi oleh variabel lain yang tidak terdapat dalam model penelitian. Variabel lain yang berpengaruh terhadap kompetensi guru, antara lain faktor internal, misalnya minat, sikap, dan kreativitas, serta faktor eksternal, misalnya kepimpinan kepala sekolah, budaya sekolah, fasilitas sekolah, dan kompensasi (Wenno, 2016). Sementara variabel lain yang berpengaruh terhadap praktik pembelajaran, antara lain (1) prior school experiences, misalnya saat guru tersebut menjadi peserta didik, guru sebelumnya, program persiapan guru, dan pengalaman mengajar sebelumnya; (2) immediate classroom situation, misalnya peserta didik, topik materi matematika, dan kendala waktu; (3) social teaching norms, misalnya keadaan sekolah, kurikulum, rekan guru, dan orang tua peserta didik; (4) matematics belief, misalnya keyakinan terhadap sifat matematika, keyakinan tentang belajar matematika dan keyakinan terhadap mengajar matematika (Raymond,1997).

Berdasarkan hasil wawancara diperoleh informasi bahwa guru merasakan mendapat banyak manfaat dari pelatihan-pelatihan yang mereka ikuti terutama pelatihan yang berkaitan langsung dengan praktik pembelajaran, namun ada guru yang sudah mencoba untuk mempraktikkannya dalam pembelajaran dan ada juga yang belum. $\mathrm{Hal}$ ini terkait dengan berbagai alasan, misalnya kendala atau keyakinan guru. Temuan tersebut sejalan dengan temuan Qablan et al. (2015) bahwa sebagian besar guru menyatakan mendapatkan manfaat dari program PKB yang diikutinya, namun dalam pengimplementasiannya hanya sedikit guru yang menggunakannya dalam pembelajaran. Temuan tersebut juga sejalan dengan temuan Sabah et al. (2014) yang menunjukkan bahwa sebagian besar guru yang mengikuti pelatihan PKB meyakini bahwa pengetahuan dan keterampilan baru di kelas sangat penting dan merupakan aspek paling penting dari PKB, namun tidak satu pun dari mereka yang mempraktikkannya di kelas. Selain itu, temuan penelitian ini juga sejalan dengan temuan Doherty (2011) yang menunjukkan bahwa para guru yang mengikuti workshop dengan materi yang berkaitan dengan teknologi pembelajaran memberikan tanggapan yang positif mengenai workshop yang diikuti, namun hanya sebagian kecil yang menerapkannya dalam praktik pembelajaran.

Penelitian ini diharapkan dapat memberikan kontribusi bagi pendidikan matematika. Hasil penelitian yang menunjukkan bahwa terdapat pengaruh yang signifikan PKB terhadap kompetensi guru matematika dan praktik pembelajaran guru matematika SMA di Kabupaten Kulon Progo diharapkan dapat semakin meyakinkan guru-guru matematika akan pentingnya mengikuti PKB yang relevan dengan profesi guru. Selain itu, diharapkan juga guruguru matematika tidak hanya berhenti hanya sampai mengikuti pelatihan saja, namun diharapkan guru-guru matematika juga berusaha mempraktikkannya dalam pembelajaran matematika. 
Theresia Veni Tri Nugraheni, Jailani

Penelitian ini tentunya memiliki keterbatasan, yaitu belum melakukan analisis keterkaitan antara PKB terhadap hasil belajar peserta didik dan belum melakukan analisis yang melibatkan faktor-faktor atau variabel-variabel lain yang berpengaruh terhadap kompetensi guru dan praktik pembelajaran. Oleh karena itu, peneliti selanjutnya dapat melakukan penelitian tentang PKB dengan menganalisis juga hubungan antara PKB terhadap hasil belajar peserta didik. Selain itu, penelitian ini belum melakukan analisis yang lebih luas tentang variabel-variabel lain selain PKB yang dapat memberikan pengaruh terhadap kompetensi guru dan praktik pembelajaran. Oleh karena itu, peneliti selanjutnya dapat melakukan penelitian tentang PKB dengan menganalisis juga hubungan antara PKB dan variabel-variabel lain yang berpengaruh terhadap kompetensi guru dan praktik pembelajaran.

\section{SIMPULAN}

Berdasarkan hasil dan pembahasan dalam penelitian ini, maka dapat disimpulkan bahwa ada pengaruh yang signifikan PKB terhadap kompetensi guru matematika SMA di Kabupaten Kulon Progo dengan nilai prediksi yang berada pada kategori sedang dan ada pengaruh yang signifikan PKB terhadap praktik pembelajaran guru matematika SMA di Kabupaten Kulon Progo dengan nilai prediksi yang berada pada kategori sedang. Sebagai tindak lanjut dari penelitian ini terdapat beberapa saran yang dapat dikemukakan. Pertama, guru matematika diharapkan memiliki kesadaran dan motivasi yang tinggi untuk terlibat aktif dalam kegiatan PKB dan mempraktikkan hasilnya dalam pembelajaran matematika. Kedua, peneliti selanjutnya dapat melakukan penelitian tentang PKB dengan menganalisis juga hubungan antara PKB terhadap hasil belajar peserta didik dan variabel-variabel lain selain PKB yang dapat memberikan pengaruh terhadap kompetensi guru dan praktik pembelajaran.

\section{DAFTAR PUSTAKA}

Akalu, G. A. (2016). Interrogating the continuing professional development policy framework in Ethiopia: A critical discourse analysis. Professional Development in Education, 42(2), 179-200. https://doi.org/10.1080/19415257.2014.940627

Ambusaidi, I., \& Yang, Y. F. (2019). The impact of teacher quality on student achievement in Oman and Taiwan. International Journal of Education and Learning, 1(2), 50-62. https://doi.org/10.31763/ijele.v1i2.39

Australian Institute for Teaching and School Leadership. (2011). Australian professional standards for teachers. http://www.aitsl.edu.au/australian-professional-standards-for-teachers/standards/list

Aziz, F., \& Akhtar, M. M. S. (2014). Impact of training on teacher's competencies at higher education level in Pakistan. International Refereed Research Journal, 5(1), 121-128.

http://www.researchersworld.com/index.php/rworld/article/view/746

Bailey, M. (2011). Policy, professionalism, professionality and the development of HR practitioners in the UK. Journal of European Industrial Training, 35(5), 487-501. https://doi.org/10.1108/03090591111138035

Bell, F. H. (1978). Teaching and learning mathematics (in secondary schools). Wm. C. Company Publishers.

Blömeke, S., \& Delaney, S. (2012). Assessment of teacher knowledge across countries: A review of the state of research. ZDM Mathematics Education, 44(3), 223-247. https://doi.org/10.1007/s11858-012-0429-7

Borko, H. (2004). Professional development and teacher learning: Mapping the terrain. Educational Researcher, 23(8), 3-15. https://doi.org/10.3102/0013189X033008003

Braund, M., Lubben, F., \& Bennet, J. (2011). Researching impact of targeted CPD on teachers' professional attitudes and classroom practices. Proceedings of The 15th Biennial of the International Study Association on Teachers and Teaching (ISATT) (pp. 93-101). University of Minho.

https://repositorium.sdum.uminho.pt/bitstream/1822/15875/1/CD-ProceedingsISATT2011.pdf

Brown, J. L. (1995). Observing dimensions of learning in classroom and schools. Association for Supervision and Curriculum Development.

BSNP. (2015). Aplikasi PAMER ujian nasional 2014/2015 [Software]. Badan Standar Nasional Pendidikan, Kemdikbud.

BSNP. (2016). Aplikasi PAMER ujian nasional 2015/2016 [Software]. Badan Standar Nasional Pendidikan, Kemdikbud. 
Buddin, R., \& Zamarro, G. (2009). Teacher qualifications and student achievement in urban elementary schools. Journal of Urban Economic, 66(2), 103-115. https://doi.org/10.1016/j.jue.2009.05.001

Chen, W., Hendricks, K., \& Archibald, K. (2011). Assessing pre-service teachers' quality teaching practices. Educational Research and Evaluation, 17(1), 13-32. https://doi.org/10.1080/13803611.2011.578008

Chin, W. W., \& Newsted, P. R. (1999). Structural equation modeling analysis with small samples using partial least squares. In R. Hoyle (Ed.), Statistical strategies for small sample research (pp. 307-341). Sage Publications.

Cohen, L., Manion, L., \& Morrison, K. (2007). Research methods in education (6th ed.). Routledge.

Collin, K., Van der Heijden, B., \& Lewis, P. (2012). Continuing professional development. International Journal of Training and Development, 16(3), 155-163. https://doi.org/10.1111/j.1468-2419.2012.00410.x

Council of Chief State School Officers. (2011). Interstate teacher assessment and support consortium (InTASC) model core teaching standards: A resource for state dialogue. Author. https://ccsso.org/sites/default/files/201711/InTASC_Model_Core_Teaching_Standards_2011.pdf

Creswell, J. W. (2012). Educational research: Planning, conducting, and evaluating quantitative and qualitative research (4th ed.). Pearson.

Croft, A., Coggshall, J. G., Dolan, M., Powers, E., \& Killion, J. (2010). Job-embedded professional development: What it is, who is responsible, and how to get it done well. National Comprehensive Center for Teacher Quality. https://learningforward.org/wp-content/uploads/2017/08/job-embedded-professional-development.pdf

Darling-Hammond, L. (2000). Teacher quality and student achievement: A review of state policy evidence. Education Policy Analysis Archives, 8(1), 1-44. https://doi.org/10.14507/epaa.v8n1.2000

Das, A. K. (2011). Emergence of open educational resources (OER) in India and its impact on lifelong learning. Library Hi Tech News, 28(5), 10-15. https://doi.org/10.1108/07419051111163848

Day, C. (2002). Developing teachers: The challenges of lifelong learning. Taylor \& Francis.

Department for Education. (2011) Teachers' standards: Guidance for school leaders, school staff and governing bodies. https://www.gov.uk/government/publications/teachers-standards

Desimone, L M. (2009). Improving impact studies of teachers' professional development: Toward better conceptualizations and measures. Educational Researcher, 38(3), 181-199. https://doi.org/10.3102/0013189X08331140

Desimone, L. M., Porter, A. C., Garet, M. S., \& Firman, B. F. (2002). Effects of professional development on teachers' instruction: Results from a three-year longitudinal study. Educational Evaluation and Policy Analysis, 24(2), 81112. https://doi.org/10.3102/01623737024002081

Doherty, I. (2011). Evaluating the impact of professional development on teaching practice: Research findings and future research directions. US-China Education Review, 5, 703-714. https://files.eric.ed.gov/fulltext/ED527691.pdf

Garson, G., D. (2016). Partial least square: Regression \& structural equation models. Statistical Publishing Associates.

Goe, L. (2007). The link between teacher quality and student outcomes: A research synthesis. National Comprehensive Center for Teacher Quality.

Gupta, K., Sleezer, C. M., \& Russ, C. F. (2007). A practical guide to needs assessment. Pfeiffer.

Guskey, T. R. (2000). Evaluating professional development. Corwin Press.

Hair, J. F., Hult, G. T. M., Ringle, C. M., \& Sarstedt, M. (2014). A primer on partial least squares structural equation modeling (PLS-SEM). Sage Publications.

Haynes, A. (2010). The complete guide to lesson planning and preparation. Continuum International Publishing Group. 
Hill, H. C., Blunk, M. L., Charalambous, C. Y., Lewis, J. M., Phelps, G. C., Sleep, L., \& Ball, D. L. (2008). Mathematical knowledge for teaching and the mathematical quality of instruction: An exploratory study. Cognition and Instruction, 26(4), 430-511. https://doi.org/10.1080/07370000802177235

Hufad, A., Pramudia, J. R., \& Supariatna, S. (2010). Studi tentang implementasi program belajar sepanjang hayat di Indonesia. Prosiding Seminar Internasional Pendidikan Luar Sekolah, Universitas Pendidikan Indonesia (pp. 1-42). http://file.upi.edu/Direktori/PROCEEDING/Seminar_Internas.NFE/STUDI_TENTANG_IMPLEMENTASI_PROGRA M_BELAJAR_SEPANJANG_HAYAT_DI_INDONESIA.pdf

Kartowagiran, B. (2011). Kinerja guru profesional (guru pasca sertifikasi). Cakrawala Pendidikan, 30(3), 463-474. https://doi.org/10.21831/cp.v3i3.4208

Kemendiknas. (2010). Pembinaan dan pengembangan profesi guru buku 1: Pedoman pengelolaan pengembangan keprofesian bekelanjutan (PKB). Direktorat Jenderal Peningkatan Mutu dan Tenaga Kependidikan.

Klercq, J. (2016). Netherlands. In B. Findsen \& M. Formosa (Eds.), International perspectives on older adult education (pp. 285-295). Springer International Publishing.

Kunter, M., Baumert, J., Voss, T., Klusman, U., Ritchter, D., \& Hachfeld, A. (2013). Professional competence of teachers: Effects on instructional quality and student development. Journal of Educational Psychology, 105(3), 895-820. https://doi.org/10.1037/a0032583

Kyriacou, C. (2007). Essential teaching skills (3rd ed.). Nelson Thornes.

Maulipaksi, D. (2016). 7 Provinsi raih nilai terbaik uji kompetensi guru 2015. http://www.kemdikbud.go.id/main/blog/2016/01/7-provinsi-raih-nilai-terbaik-uji-kompetensi-guru-2015

Miles, M., B., Huberman, A. M., \& Saldan J. (2014). Qualitative data analysis: A methods sourcebook (3rd ed.). Sage Publication.

Opfer, V. D., \& Pedder, P. (2010). Benefits, status and effectiveness of continuous professional development for teachers in England. The Curriculum Journal, 21(4), 413-431. https://doi.org/10.1080/09585176.2010.529651

Ozdemir, S. M. (2013). Exploring the Turkish teachers' professional development experiences and their needs for professional development. Mevlana International Journal of Education, 3(4), 250-264. http://dx.doi.org/10.13054/mije.13.56.3.4

Phin, C. (2014). Teacher competence and teacher quality in Cambodia's educational context linked to in-service teacher training: an examination based on a questionnaire survey. International Journal of Educational Administration and Policy Studies, 6(4), 62-69. https://doi.org/10.5897/IJEAPS2013.0326

Powell, E. D., Furey, S., \& Scott-Evans, A. (2003). Teachers' perceptions of the impact of CPD: an institutional case study. Journal of In-service Education, 29(3), 389-404. https://www.tandfonline.com/doi/pdf/10.1080/13674580300200225

Power, C. N., \& Maclean, R. (2013). Lifelong learning: Meaning, challenges, and opportunities. In R. Maclean, S. Jagannathan, \& J. Sarvi, (Eds.), Skills development for inclusive and sustainable growth in developing AsiaPacific, technical and vocational education and training: Issues, concerns and prospects 19 (pp. 29 -42). Springer.

PPPPTK Matematika. (2015). Hasil UKG tahun 2015 [Tidak diterbitkan]. Kemendikbud.

Pratiwi, E. N., \& Mahmudah, R. A. (2012). Peningkatan daya saing tenaga kerja Indonesia melalui korelasi input penunjang tenaga kerja dalam menghadapi MEA 2015. Economic Development Analysis Journal, 2(2), 1-7. https://doi.org/10.15294/edaj.v2i2.1661

Presiden Republik Indonesia. (2008). Peraturan Pemerintah Republik Indonesia Nomor 74 Tahun 2008 tentang Guru. http://simpuh.kemenag.go.id/regulasi/pp_74_08.pdf 
Qablan, A., Mansour, N., Alshamrani, S., Sabbah, S., \& Aldahmash, A. (2015). Ensuring effective impact of continuing professional development: Saudi science teachers' perspective. Eurasia Journal of Mathematics, Science \& Technology Education, 11(3), 619-631. https://doi.org/10.12973/eurasia.2015.1352a

Raymond, A. (1997). Inconsistency between a beginning elementary school teacher's mathematics beliefs and teaching practices. Journal Research in Mathematics Education, 28(5), 550-576. https://www.jstor.org/stable/749691

Sabah, S. A., Fayez, M., Alshamrani, S. M., \& Mansour, N. (2014). Continuing professional development (CPD) provision for science and mathematics teachers in Saudi Arabia: Perceptions and experiences of CPD providers. Journal of Baltic Science Education, 13(3), 91-104. http://oaji.net/articles/2015/9871437062396.pdf

Seebruck, R. (2015). Teacher quality and student achievement: A multilevel analysis of teacher credentialization and student test scores in California high schools. McGill Sociological Review, 5, 1-18. https://www.mcgill.ca/msr/files/msr/seebruck_2015.pdf

Shah, F. H., Khan, U. A., \& Shamed, I. (2015). The impact of continuous professional development (CPD) program on teachers' professional development in Pakistan. FWU Journal of Social Sciences, 9(1), 99-105. https://files.eric.ed.gov/fulltext/EJ1244673.pdf

Stronge, J. H., Ward, T. J., Tucker, P. D., \& Hindman, J. L. (2007). What is the relationship between teacher quality and student achievement? An exploratory study. Journal of Personnel Evaluation in Education, 20(3),165-184, https://doi.org/10.1007/s11092-008-9053-z

Suhr, D. (2008). Step your way through path analysis. https://www.lexjansen.com/wuss/2008/pos/pos04.pdf

UNDP. (2015). Human development report 2015: Work for human development. Author. http://hdr.undp.org/en/2015-report/download

Wallace, M. R. (2009). Making sense of the links: Professional development, teacher practices, and student achievement. Teachers College Record, 111(2), 573-596. http://www.tcrecord.org/Content.asp?Contentld=15224

Wenno, I. H. (2016). Analysis of factors affecting teacher competence physics science SMP in the district of West Seram Maluku Province. International Journal of Science and Research, 5(6), 1061-1067. http://dx.doi.org/10.21275/v5i6.NOV164349

Wibowo, E., \& Jailani, J. (2014). Analisis kesulitan guru matematika SMP dalam pengembangan keprofesian di Kabupaten Wonosobo. Jurnal Riset Pendidikan Matematika, 1(2), 202-215. https://doi.org/10.21831/jrpm.v1i2.2676

Widodo, K. S., Widodo, J., \& Masrukan, M. (2015). Pengembangan model pendidikan dan pelatihan (diklat) partisipatif integratif kolaboratif (pikola) untuk meningkatkan kompetensi professional untuk meningkatkan kompetensi profesional guru fisika SMA. Jurnal Educational Management, 4(2), 116-124. https://journal.unnes.ac.id/sju/index.php/eduman/article/view/9854/6339 